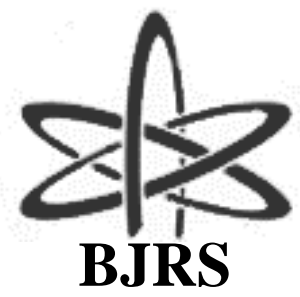

BRAZILIAN JOURNAL

$\mathrm{OF}$

RADIATION SCIENCES

08-03A (2020) 01-17

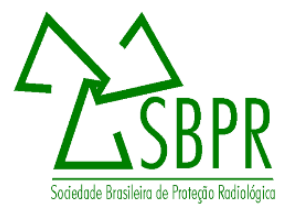

\title{
RELAP5 Modeling of a Siphon Break Effect on the Brazilian Multipurpose Reactor
}

\author{
Humberto Vitor Soares, Antônio Belchior Jr., Roberto Longo Freitas \\ Amazônia Azul Tecnologias de Defesa S.A. -AMAZUL \\ humberto.soares@amazul.gov.br
}

\begin{abstract}
This work presents the thermal-hydraulic simulation of the Brazilian Multipurpose Reactor (RMB) using the RELAP5/Mod3 code. The RMB will provide Brazil with a fundamental infrastructure for the national development on activities of the nuclear sector in the areas of social, strategic, industrial applications and scientific and technological development. A RELAP5/Mod3 code model was developed for thermal-hydraulic simulation of the RMB to analyze the phenomenology of the Siphon Breakers device (four flap valves in the cold leg and one open tube for the atmosphere in the hot leg) during a Loss of Coolant Accident (LOCA) at different points in the primary circuit. The Siphon Breaker device is an important passive safety system for research reactors in order to guarantee the water level in the core under accidental conditions. Different simulations were carried out at different location in the Core Cooling System (CCS) of the RMB, for example: LOCA before the CCS pumps with and without pump trip and LOCA after the CCS pumps and the heat exchanger. In all RELAP5/Mod3 code simulations, the Siphon Breaker device's performance after a LOCA was effective to allow enough air to enter the outlet pipe of the CCS in order to break the siphon effect and preventing the pool level from reaching the riser (chimney) and the RMB core discovering. In all cases, the reactor pool level stabilized at about $5.5 \mathrm{~m}$ after the end of the LOCA simulation and the fuel elements were kept underwater and cooled.
\end{abstract}

Keywords: RMB, RELAP5, LOCA, Siphon Breaker. 


\section{INTRODUCTION}

The Brazilian Nuclear Energy Commission (Comissão Nacional de Energia Nuclear-CNEN) is leading the project of the Brazilian Multipurpose Reactor (RMB) aimed to be projected, constructed, and operated to attend the present Brazilian needs for a multipurpose neutron source, which will be able to supply the radioisotope demand, carrying out material tests, scientific development, commercial, and medical applications with the use of neutron beams.

Currently, the RMB project is in detail engineering design phase, which is being done by the engineering companies INVAP (Argentina), AMAZUL (Brazil) and IPEN (Brazil).

In the present work, a nodalization for the Core Cooling System (CCS), service and reactor pools and the most important components of the RMB are performed using the RELAP5/Mod3 code. The Loss of Coolant Accident (LOCA) was simulated in the two different locations on the CCS of the RMB. However, the main target is to study the performance of the siphon breaker devices.

\subsection{The Brazilian Multipurpose Reactor}

The RMB will be an open pool multipurpose research reactor using low enriched uranium fuel, with a neutron flux higher than $2 \times 10^{14} \mathrm{n} /\left(\mathrm{cm}^{2} \mathrm{~s}\right)$ and $30 \mathrm{MW}_{\text {th }}$ of power, having the OPAL nuclear reactor of $20 \mathrm{MW}$, built in Australia, as main reference. The reactor core consists of MTR fuel assembly type with planar plates, cooled and moderated by light water. The reactor core has a $5 \times 5$ configuration, consisting of 23 fuel elements of $\mathrm{U}_{3} \mathrm{Si}_{2}$ dispersion-type in aluminum, having an average density of $3.7 \mathrm{gU} / \mathrm{cm}^{3}$ and enrichment of $19.75 \%$ of U-235. Two internal positions are available within the core for in core irradiation.

A heavy water tank, which acts as a neutron reflector surrounds three quarters of the chimney in the core area, working as reflector and enabling the extraction of neutron beams and the placement of materials for irradiation. In the remaining quarter there is beryllium that also works as reflector. The heavy water temperature will be controlled by a dedicated cooling system.

Figure 1 shows the model of the current concept of the RMB, where some dimensions are approximated [1]. 
Figure 1: RMB Current Concept.

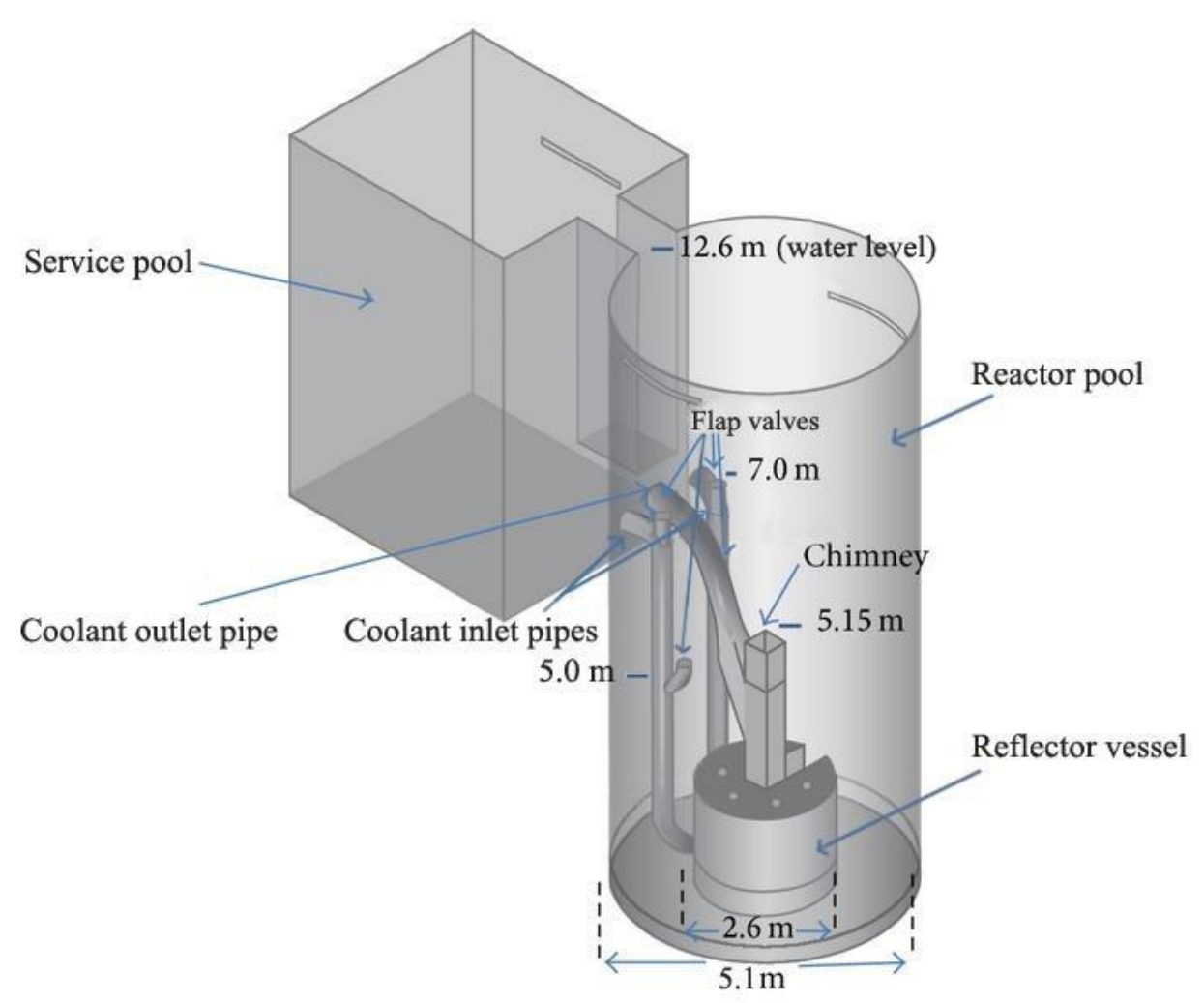

\subsection{RELAP5/Mod3 Code}

The thermal-hydraulic system code RELAP5/Mod3 [2] has been developed to best estimate transient simulation of light water power reactor systems during postulated accidents. Recent works have demonstrated that the code can be also used with good predictions for thermal-hydraulic analysis of research reactors as it can be verified in the present literature [3-10].

In previous works, the assessment and validation of thermal-hydraulic system code have been performed in order to investigate the applicability of RELAP5/Mod3.2 to evaluate safety margins of a MTR research reactor [11]. The application of RELAP5/Mod3 to research reactor has been already assessed [7], [12-14]. Furthermore, the latest's version of RELAP5/Mod3 was made suitable for research reactor applications [15]. The code RELAP5/Mod3 assessment studies have shown good agreements with some limitations on the sub cooled model [7] and [13]. 


\subsection{Siphon Breaker}

To ensure the research reactors safety, the water level of the reactor pool must be maintained above the reactor core. When a piping-system rupture accident occurs, the coolant starts to siphon out of the reactor pool until the pressure head between the inlet and outlet is removed or the siphon flow is interrupted.

A siphon breaker mechanism can be adopted as a passive safety device to protect the reactor core avoiding the lack of water in the fuel elements. These devices consist in a tube connected at the highest point in the outlet pipe of the primary cooling system and flap valves. After a LOCA, the reactor pool level begins to down reaching the level of the siphon breaker tube when being to drag air of the atmosphere into the line and, consequently, stops the siphoning flow rate.

In order to validate the capability of the RELAP5/Mod3 code to model the effects of the siphon break, an experimental theoretical evaluation was made through the experience to separate effects POSTECH of the University of Korea [16]. The very good agreement between numerical and experimental results was obtained, thus allowing the RELAP5/Mod3 code to represent the main phenomena resulting from the performance of the siphon break.

\section{THERMAL-HYDRAYLIC MODEL}

Figure 2 shows the mainly components of the Core Cooling System (CCS) of the RMB. The coolant $\left(3100 \mathrm{~m}^{3} / \mathrm{h}\right)$ enters in the lower plenum that it is directed to the core. The light water of the reactor pool enters in the chimney, $400 \mathrm{~m}^{3} / \mathrm{h}$ (about $13 \%$ of the core flow) and sum with the coolant of the reactor core. The mass flow in the coolant outlet pipe is $3500 \mathrm{~m}^{3} / \mathrm{h}$, which is conducted to decay tank, where the large dimensions and the geometric allows the water spend about $200 \mathrm{~s}$ to goes out of this tank satisfying the required time for the $\mathrm{N}_{16}$ decay.

Going out of the decay tank, the coolant is pumped to pump A and pump B, where the pump C is maintained in standby mode. Each pump has its own heat exchanger. There is a line (no showed on the Figure 2) which conducts $400 \mathrm{~m}^{3} / \mathrm{h}$ to another circuit called In Confinement Primary Cooling System (ICPCS), where inject water in a toroid located on the bottom of the reactor pool. 
Figure 2: Simplified scheme of the Core Cooling System (CCS) of the RMB.

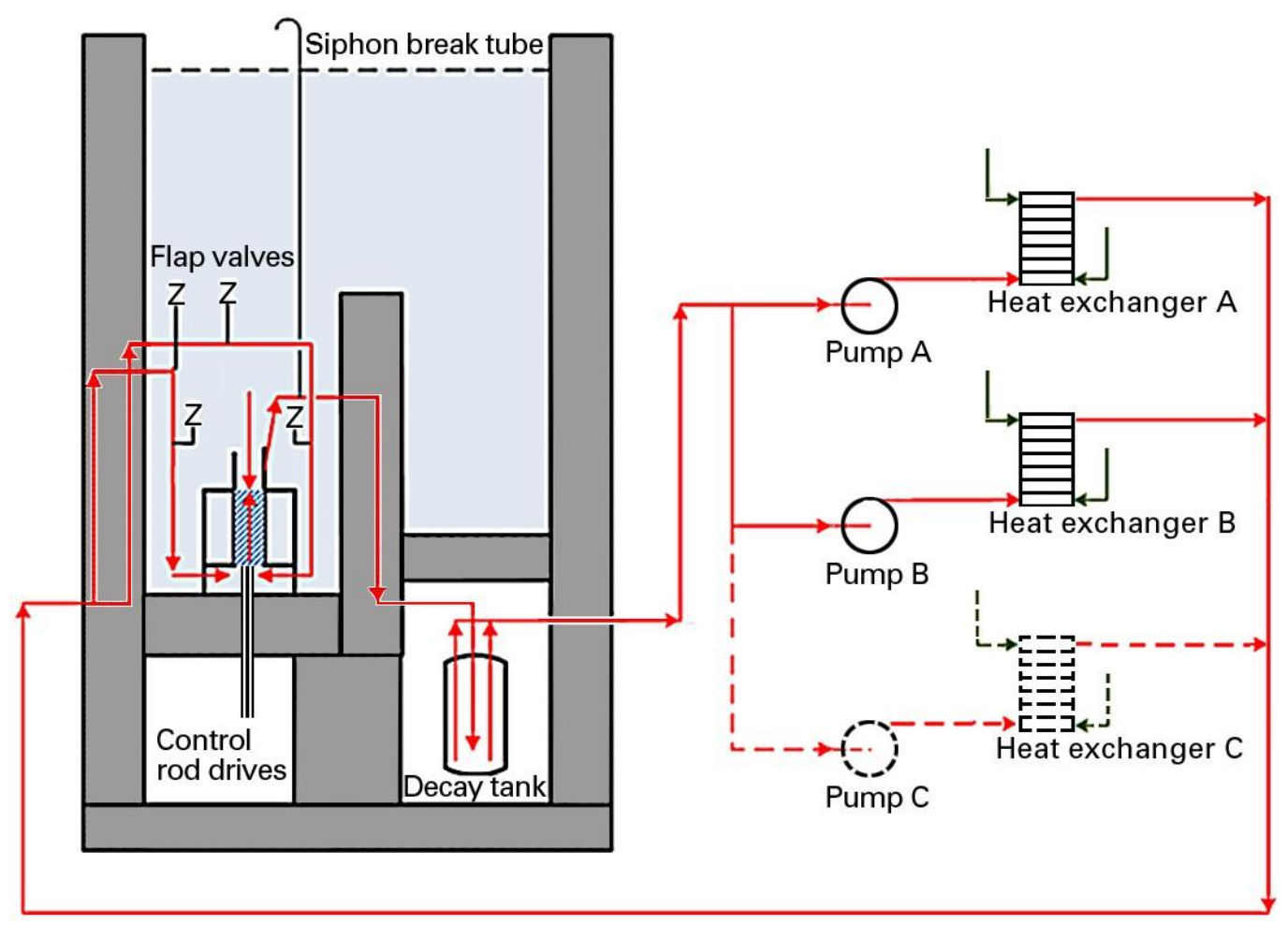

Figure 3 shows the RELAP5/Mod3 nodalization developed in [17], during the conceptual project and currently updated to simulate the CCS of the RMB. Table 1 shows the correspondence between the main components on the CCS and their equivalent components in the RELAP5/Mod3 nodalization scheme.

The reactor pool was modeled as a large cylinder extending from the bottom (level $0.0 \mathrm{~m}$ ) up to water surface level (level $+12.6 \mathrm{~m}$ ). In the RELAP5/Mod3 nodalization, was used two pipe components (100 and 130) composed by twenty volumes each one. The heat generated by the reactor core in one side of the pool (100) leads to water circulation inside the pool through the cross junctions between the two pipes. It contains all the internal components such as the core, the irradiation rigs (not modeled), the chimney, inlet and outlet pipes and the flap valves.

The service pool was modeled using a pipe component (150) with twelve volumes. Volume 140 is a branch component, which represents the upper pool surface, which is in contact with the 
atmosphere. Volume 190 is a component (Time Dependent Volume) which has an atmospheric pressure and ambient temperature that simulates the atmosphere on the top of pool surface.

Component 300 represents the core inlet lower plenum, which conducts the light water to the core (component 316). The core has one hydrodynamic channel with only one Heat Structure (HS) associated to it representing all fuel assemblies. The core is divided in five axial volumes. The heated water by core goes through the components 320 and 330, which it is mixed with a small downward flow coming from the pool through the chimney (component 340).

The siphon breaker tube (160) it is connected on the top of the last volume of the component 350 and the other side is open to the atmosphere (component 140). The coolant outlet pipe (component 350) goes out of the reactor pool on the level $+7.00 \mathrm{~m}$.

Figure 3: RMB nodalization for RELAP5/Mod3 (adapted from [17]).

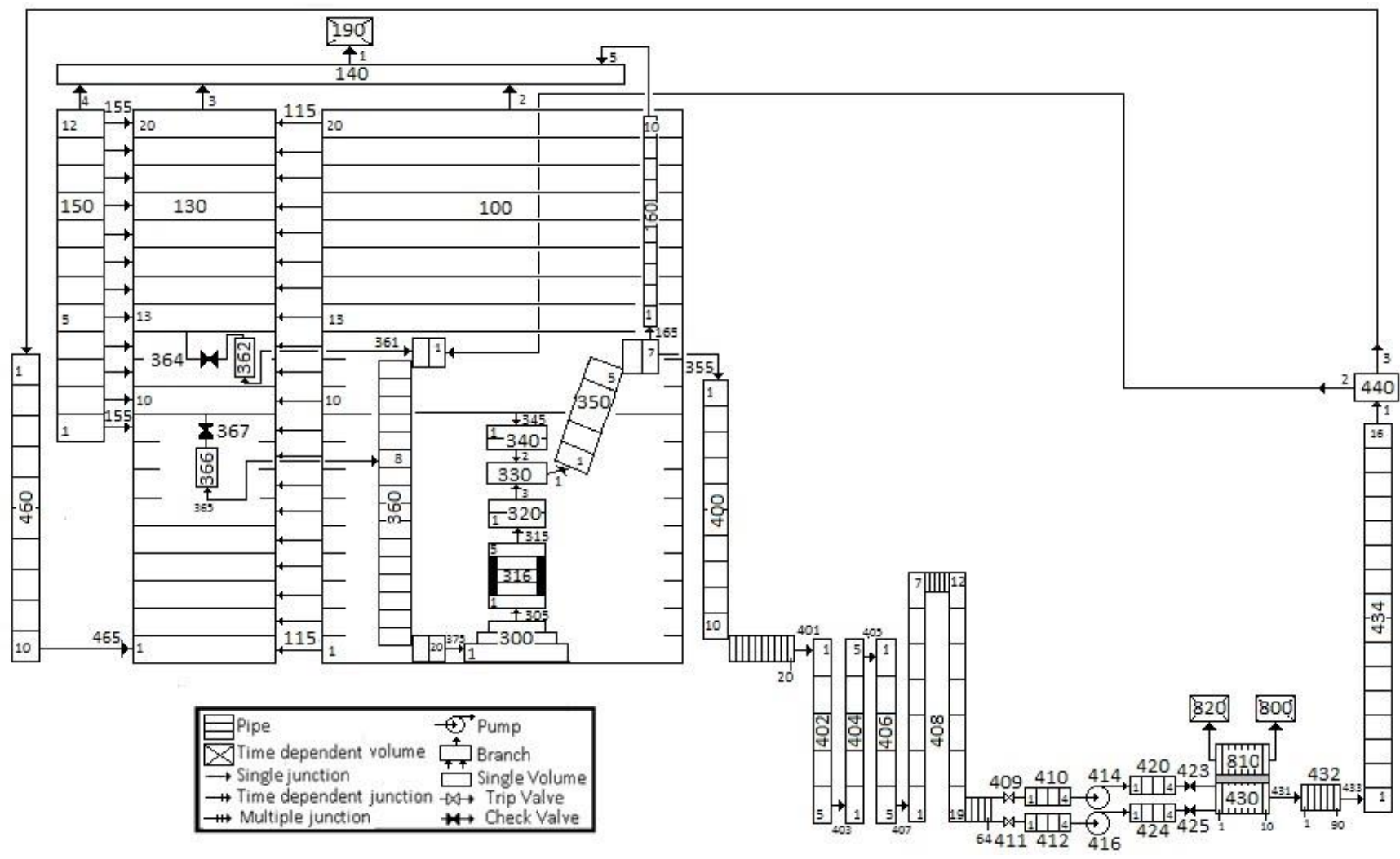


Table 1: Main nodalization components and their input identifier number from RELAP5 model.

Components

Reactor pool

Service pool

Siphon breaker tube

Pool atmosphere simulator

Lower plenum

Reactor core

Riser

Riser chimney

Coolant inlet pipe

Flap valves

Coolant outlet pipe

Decay tank

Pumps

Primary side of the heat exchanger

Secondary side of the heat exchanger

\section{Identifier on the RELAP5/Mod3 nodalization}

100 and 130

150

160

190

300

316

$320,330,340$ and 350

340

360

364 and 367

400

402, 404 and 406

414 and 416

430

800,810 and 820

The coolant pass through the component 400 and enter on the top of the decay tank $(402-406)$ and follow to long straight path (about $45.0 \mathrm{~m}$ ) in direction on the pumps (414 and 416). These pumps are located at level $-5.1 \mathrm{~m}$ (in this RELAP5/Mod3 nodalization). The pump motor torque is controlled in the model by a trip signal, thus allowing simulation of an electric power outage. After electric power is removed from the motor, the pump coasts down according to its torque and moment of inertia (which includes the flywheel). The pumps dynamic characteristics correspond to those of a Bingham Company pump included in the RELAP5/Mod3 code. Nominal head and flow rate, speed, absorbed power and moment of inertia, though, correspond to actual values for the CCS pumps.

In the RMB project there are four flap valves located at the inlet pipes, however, the RELAP5/Mod3 nodalization of the RMB presented on the Figure 3, shows two flap valves. The valve 367 (check valve type), was connected in a position below of the coolant inlet pipe 
(component 360). Both valves allow the natural circulation on the reactor. Valve 364 is connected in the upper of the coolant inlet pipe (360). This valve (364) works as a siphon break device. In the normal operation of the reactor with no perturbation in the flow rate (steady state) the 364 and 367 valves remain closed. On the other hand, in some transients where a flow rate reduction occurs it can lead to a pressure drop in the inlet pipes allowing these valves to open.

In the RMB nodalization presented in this work, was modeled just one heat exchanger (component 430 - primary side) for the both pumps. The heat exchanger removes an amount of heat that depends on the secondary side (component 810 ) inlet temperature and flow rate.

\section{LOSS OF COOLANT ACCIDENT CALCULATION ON THE RMB}

The Loss of Coolant Accident (LOCA) is one of the most important design basis accidents. In spite of the probability of large break accident in research reactors occurs is very low it might cause core damages in the case of its occurrence. To avoid this type of accident, use of a siphon breaker has been suggested as one nuclear safety device for research reactors.

In the case of LOCA, a time-dependent volume was introduced as a boundary condition to simulate the break discharge. This volume was connected to the CCS by a junction with a crosssectional area corresponding to the size of the simulated break.

Figure 4 shows the part of the Figure 3, highlighting the two positions of the LOCA. To simulate the accident was introduced a trip valve (435) and a time-dependent volume (437), which simulates a recipient that receive the coolant during the simulated accidents.

The locations of the cases simulate was:

1 - LOCA at CCS pump suction line (component 408-19);

2 - LOCA at CCS pump discharge line (component 434-01).

Analyses of both cases are very similar, because in the beginning of LOCA the coolant goes out by rupture and the water level of the reactor pool drops until the upper flap valves and the siphon break tube injected air on the coolant outlet pipe, which will act as siphon breakers and will prevent the water level from dropping below level the reactor chimney.

All transient events started at 1000 seconds after simulating steady state at $30 \mathrm{MW}$. To simulate the First Shutdown System (FSS) action (insertion of all control plates in core) using the 
RELAP5/Mod3, a negative reactivity of $\$ 10$ is inserted in 0.5 seconds of simulation time. This process starts when the mass flow in core inlet decreases below $20 \%$ of steady state value or if the reactor pool level decreases below $12.0 \mathrm{~m}$.

Figure 4: Part of the RMB nodalization for RELAP5/Mod3 highlighting the position of the LOCA events.

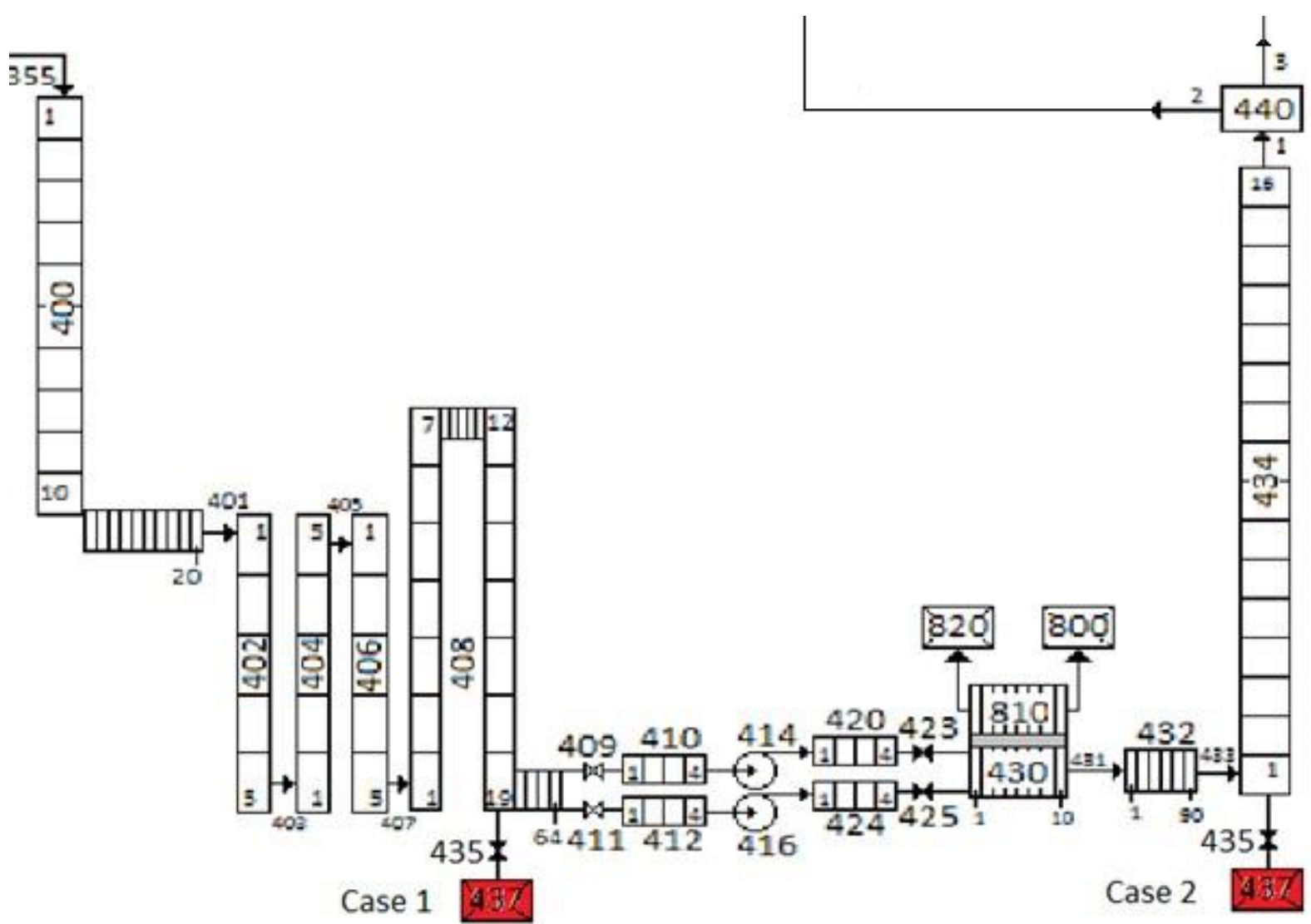

\subsection{Case 1: LOCA at CCS Pump Suction Line}

Aiming studying the behavior of the LOCA on the CCS pump suction line, two scenarios were simulated:

a: No pumps trip - pumps continue to run normally;

b: With pumps trip - After the reactor shutdown, a trip runs in the pump stopping it. In this event, the pump flywheels provide decreasing flow during shutdown.

Figure 5 depicts the RMB reactor power. Both curves show the same behavior, about 40 seconds after the beginning of the accident, when the reactor trip was triggered. The reactor pool 
water level decreased under the $12.0 \mathrm{~m}$, as can be seen in the Figure 6 . The reactor power curves are independent of the CCS pumps shutdown (Figure 5), however, the reactor pool water level is a bit different (Figure 6). When the CCS pumps die (with pumps trip), the reactor pool water decrease a little faster and stabilizes some centimeters below of the black curve (no pumps trip). The rupture of the pipe occurs before the both pumps, so, the shutdown of the CCS pumps contributes to a large amount of coolant escaping through the pipe.

Figure 5: Reactor Power Evolution.

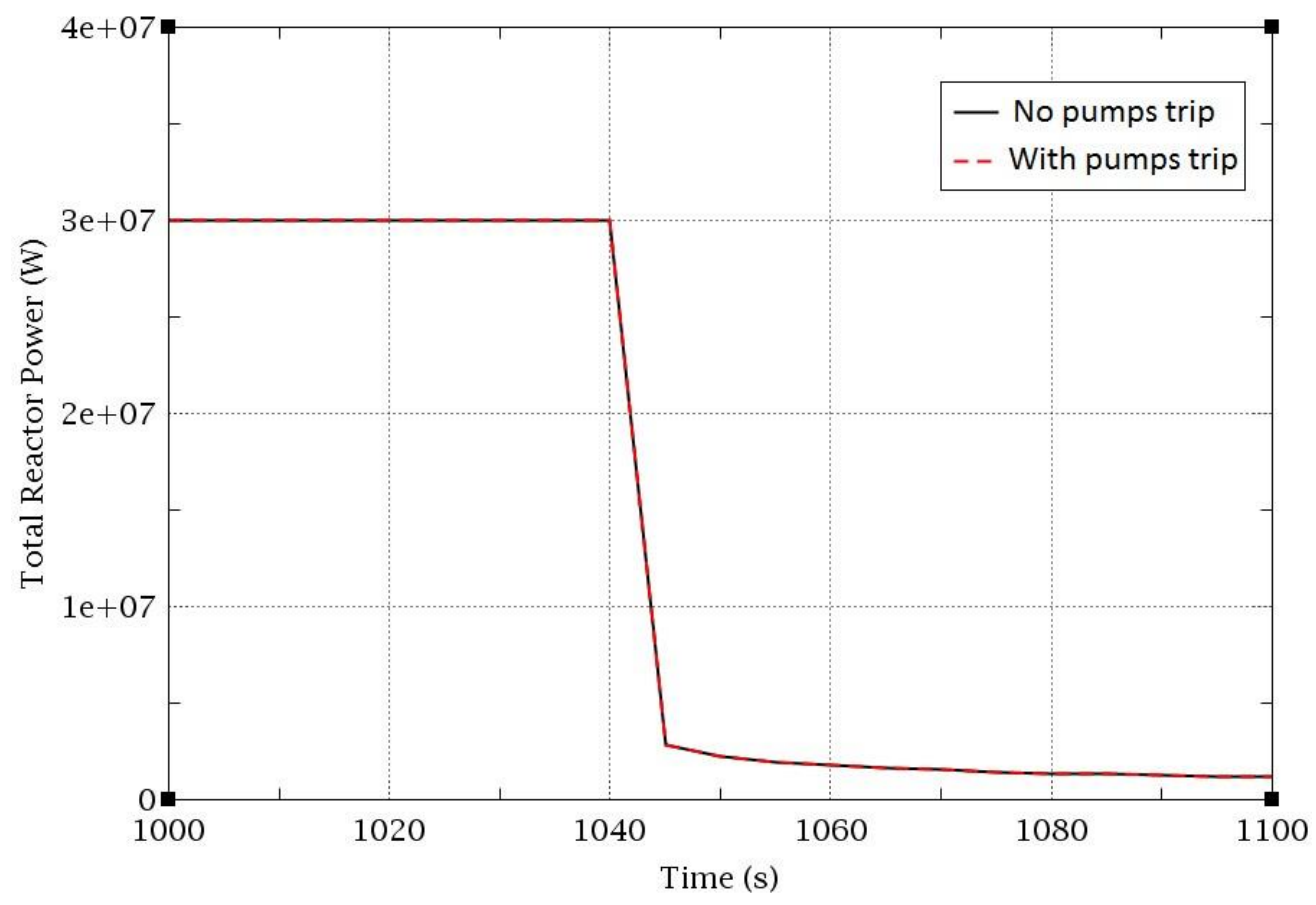

Figure 7 depicts the pump-414 velocity curves. The pump-416 is identical to the pump-414 and is no necessary to show its curves on the figure, and then, both pumps (414 and 416) have the same behavior. The red curve shows the coast down by the inertia of the flywheel soon after of the trip reactor together with the pump. 
Figure 6: Reactor Pool Water Level Evolution.

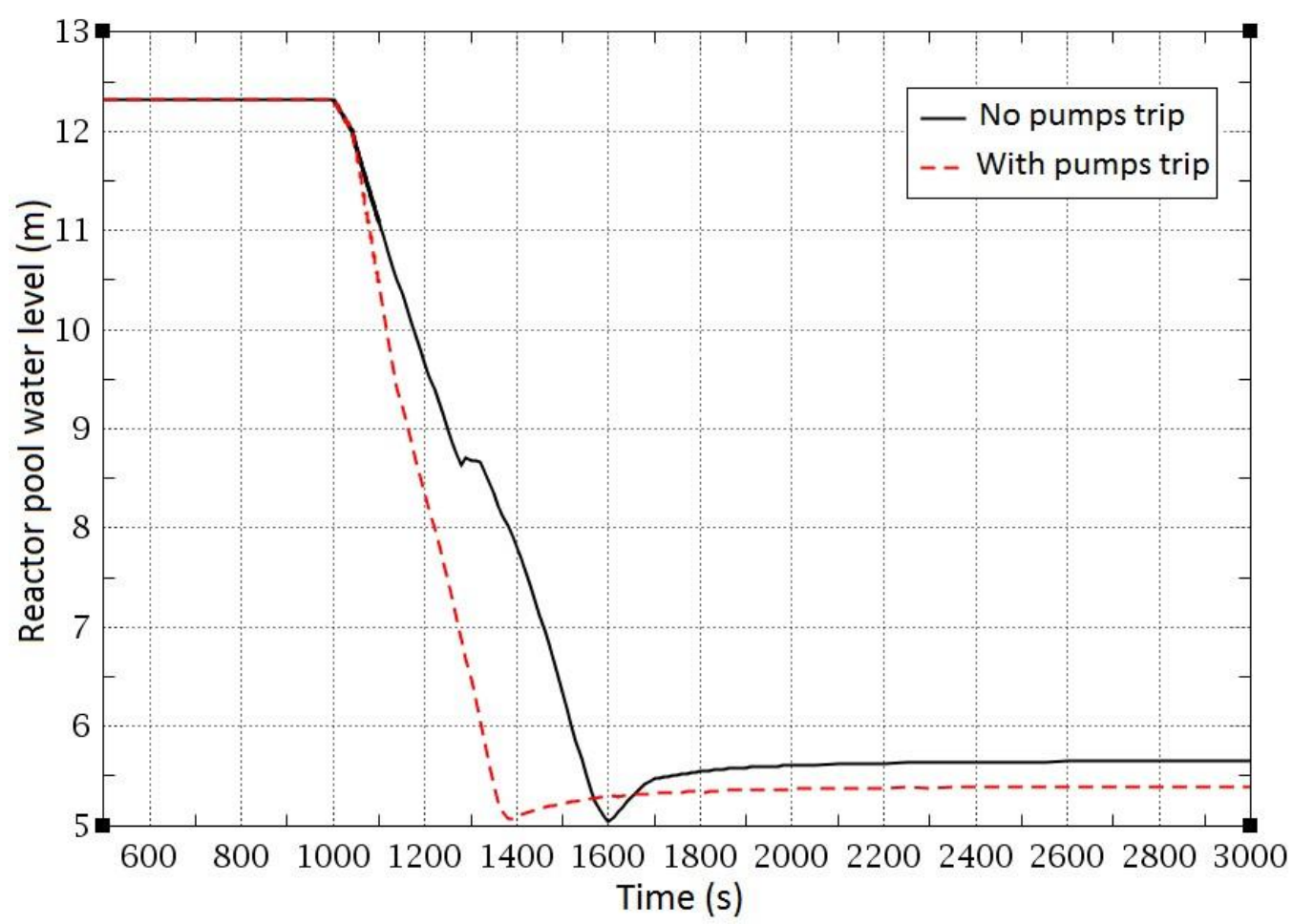

Figure 7: Pump 414 Velocity Evolution.

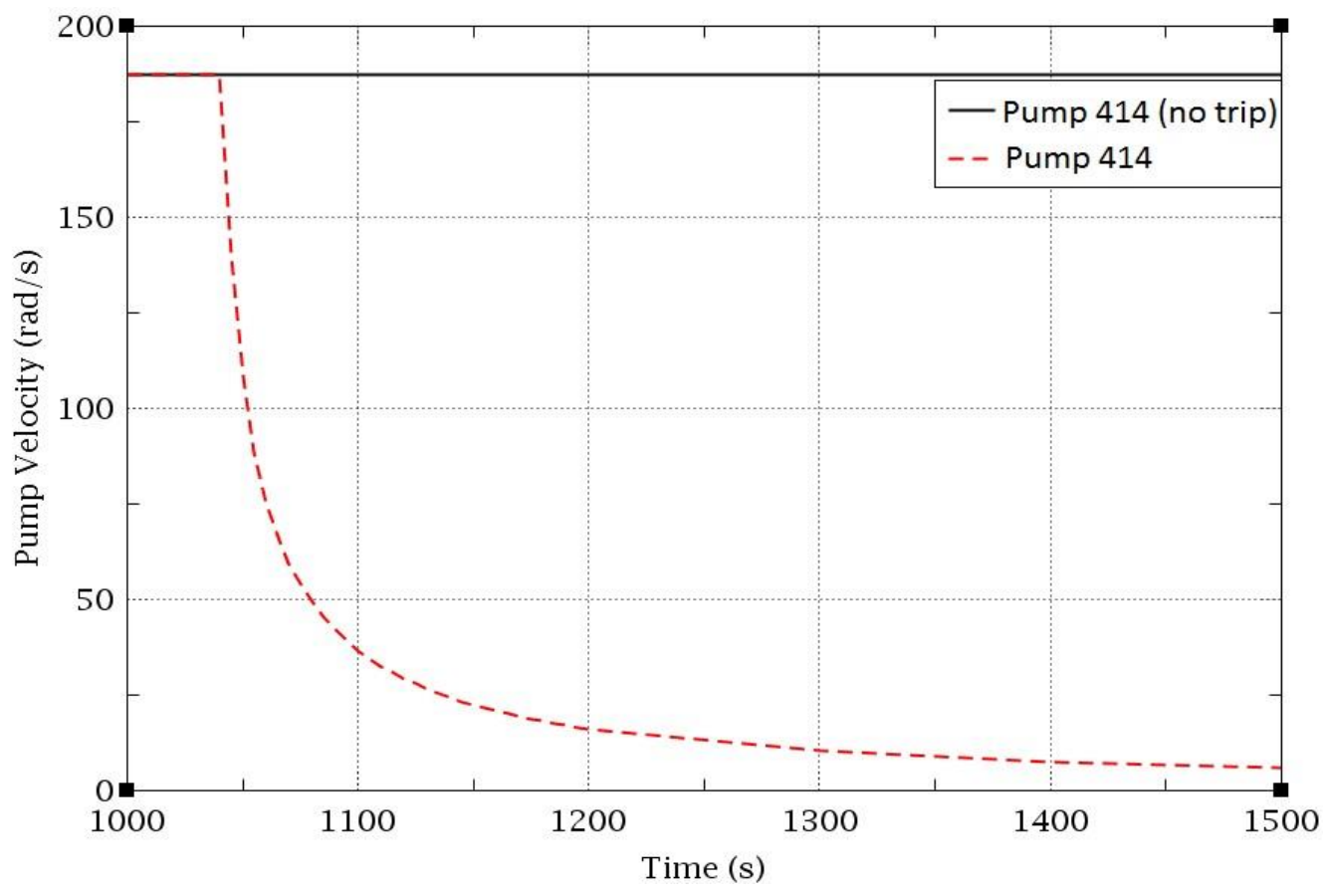


Figure 8 shows the mass flow rate through the rupture (valve 435) during the first 800 seconds of the transient. As can be seen on the Figure 8, the beginning of the transient is identical for the both scenarios (no pumps trip and with pumps trip), however when turned off the pumps (red curve) the mass flow rate is larger and consequently the reactor pool water level decrease faster. With the pumps trip the siphon breaker phenomenon occurs about 430 seconds after of the transient, ceasing the mass flow on the rupture.

The time difference to reach the siphon break devices in the both scenarios is about 200 seconds, showing that the pumps trip activation is worse to reactor safe. The abrupt decrease at the black curve (no pumps trip) at the time 1300 seconds is due the pumps head loss, as can be observed on the Figure 9. The pressure loss on the CCS causes oscillations due the air arrival on the both pumps (414 and 416).

Figure 8: Mass flow rate evolution for the rupture (valve 435).

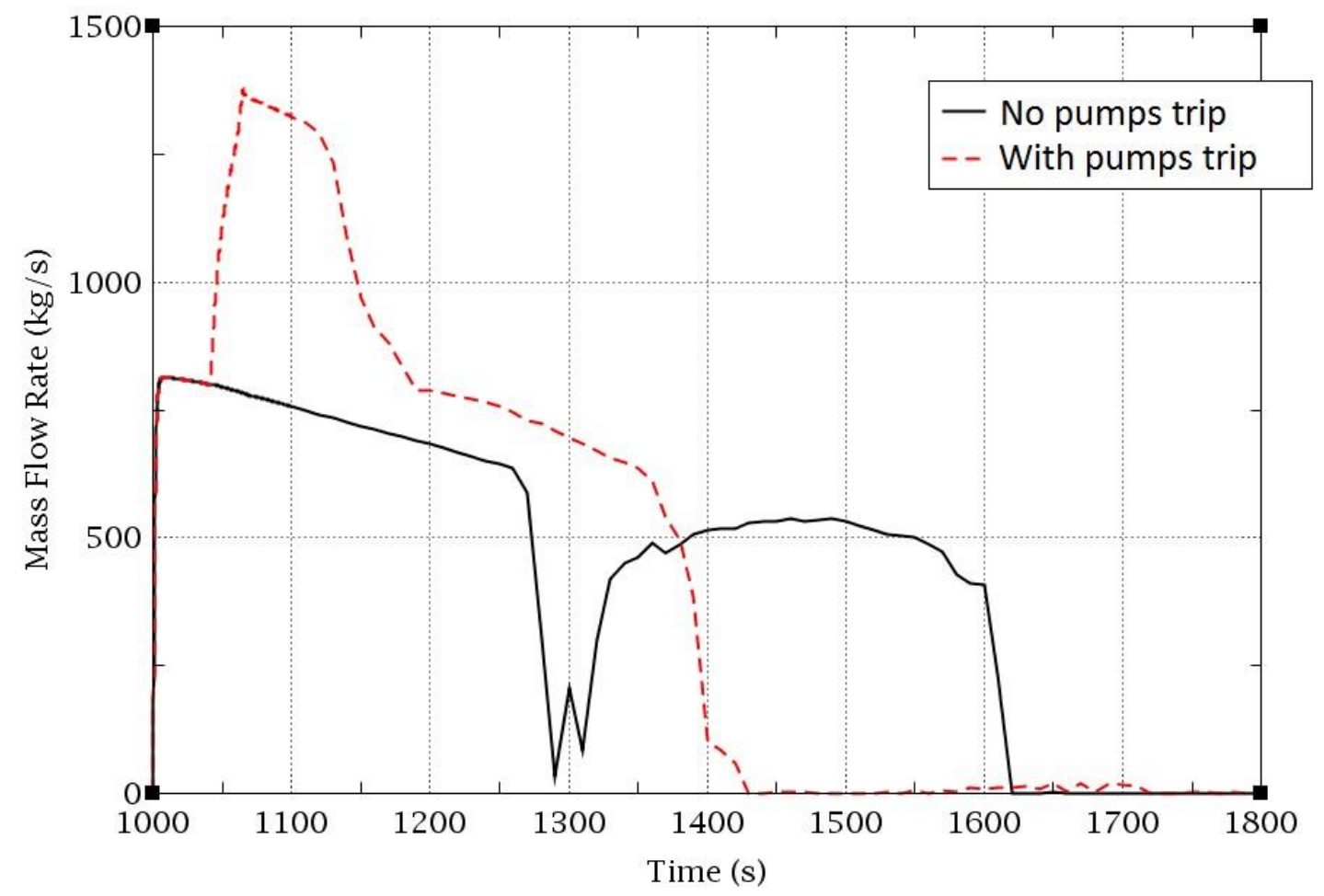


Figure 9: Pump head evolution for CCS pumps.

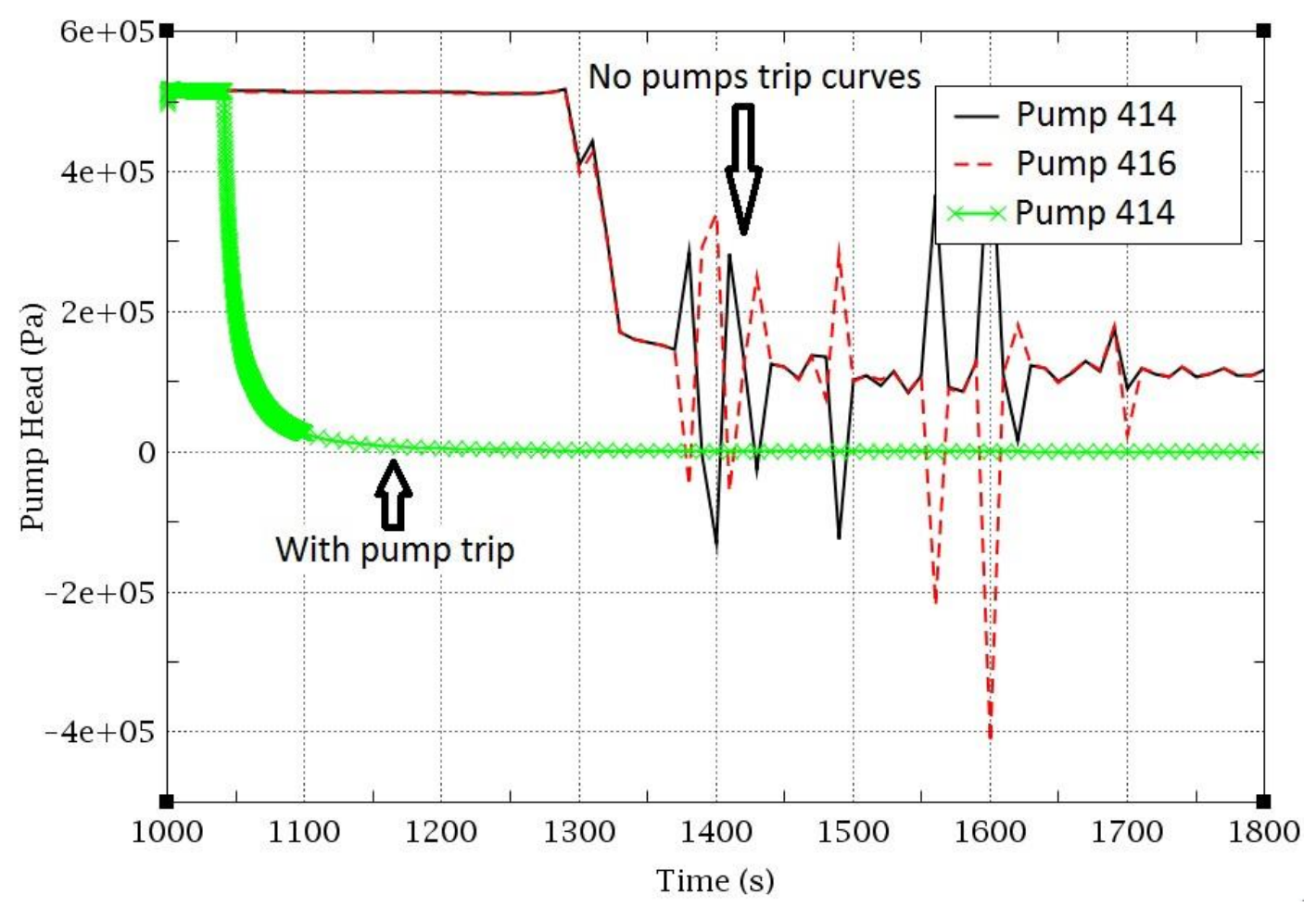

\subsection{Case 2: LOCA at CCS Pump Discharge Line}

In order to study the effectiveness of the siphon break devices, it was simulated four scenarios to LOCA at CCS pump discharge line (pipe 434, volume 01 on the nodalization RELAP5):

a: No pumps trip;

b: Pumps trip;

c: Pumps trip and no siphon break tube 160;

d: Pumps trip and no siphon break devices (valve 364 and tube 160).

Figure 10 shows the reactor pool water level for all the scenarios. Curves that do not have siphon break tube ("c" and "d") reached the reactor chimney level $(5.1 \mathrm{~m})$ and the flap valve 367 , finishing the natural circulation on the reactor.

Scenarios "a" and "b" maintained the water level above of the flap valve 367 and consequently its opening provide mass flow enough to cooling the fuel elements on the core, ensuring the natural circulation mode on the reactor. During the natural circulation, the flow of the just one flap valve is sufficient to remove decay power of the core. 
Figure 10: Reactor Pool Water Level Evolution.

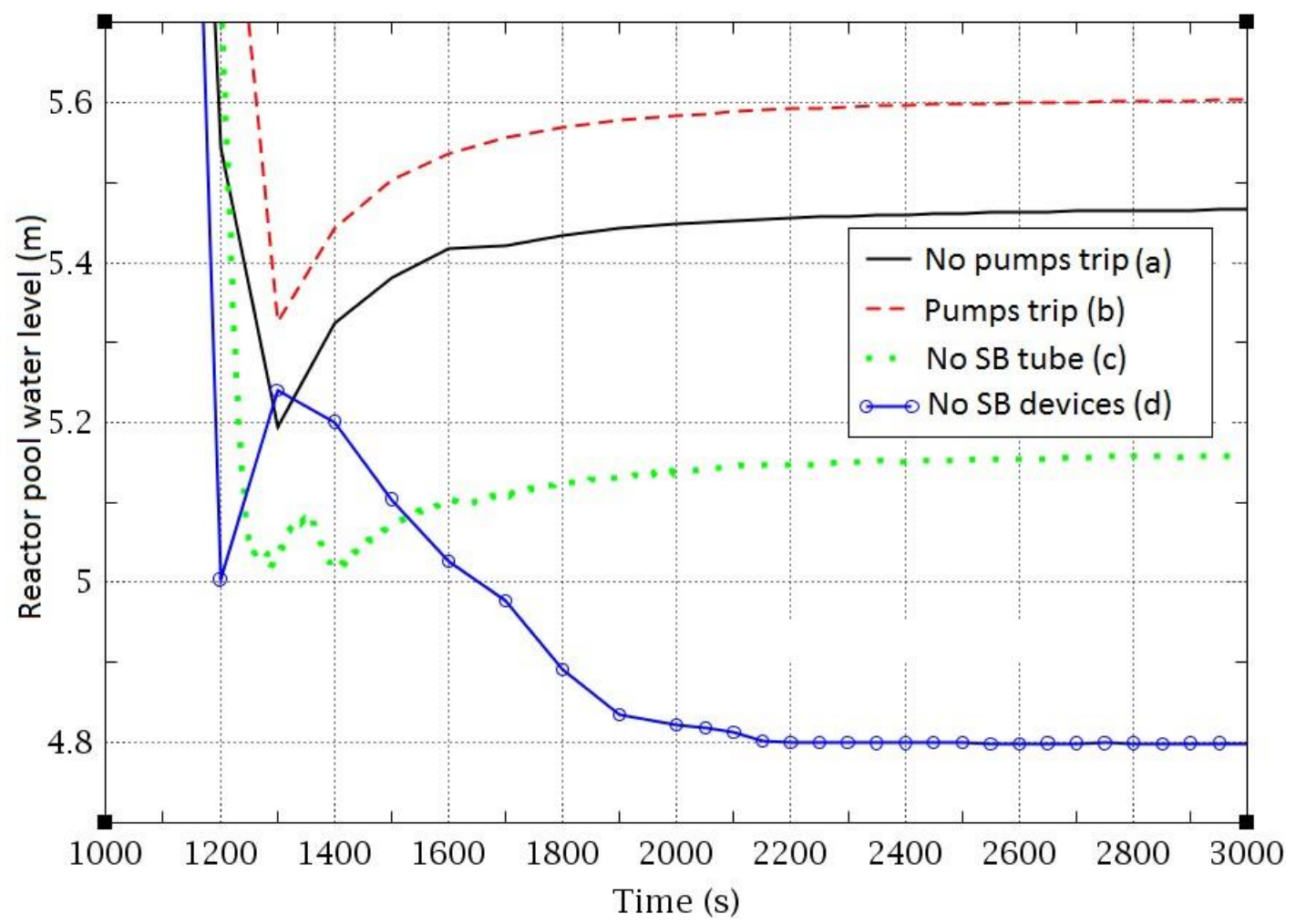

The lack on the core mass flow on the scenarios "c" and "d" causes increase of the fuel temperature and consequently increase of the coolant temperature on the core, as can be seen in the Figure 11. While the scenarios "a" and "b" do not reach the saturation temperature.

To mitigate this accident, the RMB design has a system that supplies water to maintain the core with water. The Emergency Make-Up Water System (EMWS) is a passive system that will operate, during the first 24 hours, only under scenarios defined as "Events Beyond Design Basis" (EBDB).

The system provides a way to remove the core decay heat in case of a Loss of Coolant event resulting in the decrease of the pool water level beyond the siphon-breakers level, (i.e., below the upper end of the chimney). The EMWS injects water under gravity into the two legs of the CCS inlet pipelines, through the opening of, at least, one of the two float valves. The EMWS is designed to ensure continuous water injection to the core for twenty-four hours. It is possible to maintain the system operation for more that twenty-four hours, by refilling the EMWS storage tanks with water from an external source of water. 
Figure 11: Core outlet temperature evolution.

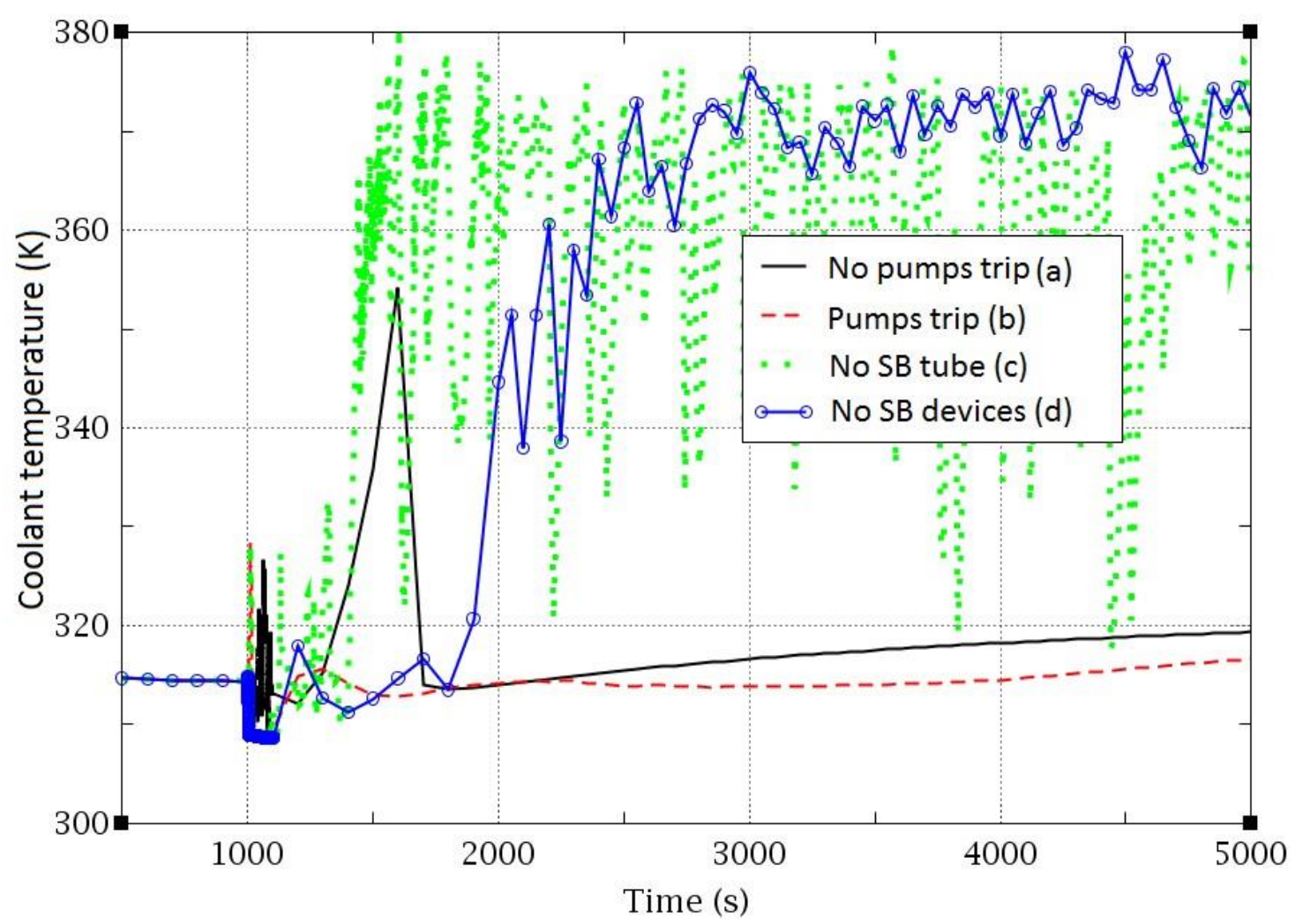

\section{CONCLUSION}

This work analyzed the phenomenological behavior of a LOCA transient in the Brazilian Multipurpose Reactor in different positions of the primary circuit with the thermal-hydraulic code RELAP5/Mod3. The results from the numerical simulation showed that the siphon break devices are efficient to ensure the fuel physical integrity and consequently the RMB remains in a safe state during the LOCA transients.

Although the Siphon Breaker device is a simple component, this device is reliable and is an important passive safety system for research reactors. 


\section{ACKNOWLEDGMENT}

The authors would like to thank IPEN/CNEN-SP and AMAZUL in acknowledgement of their structures and willing to push forward science and nuclear technology in Brazil.

\section{REFERENCES}

[1] NAVARRO, M. A.; SCHWEIZER, F. L. A.; SANTOS A. A. C. Numerical investigation in the Brazilian Multipurpose Reactor pool. Proceedings of the International Nuclear Atlantic Conference (INAC 2011), Belo Horizonte, Brazil, 2011.

[2] US NRC, UNITED STATES NUCLEAR REGULATORY COMMISSION. RELAP5/MOD3.3 Code Manuals. Idaho National Engineering Laboratory, NUREG/CR-5535, 2001.

[3] ANTARIKSAWAN, A. R.; HUDA, M. Q.; LIU, T.; ZMITKOVA, J.; ALliSON, C. M.; HOHORST J. K. Validation of RELAP/SCAPSIM/MOD3.4 for research reactor applications. Proceedings of the 13th International Conference on Nuclear Engineering, Beijing, China, 2005.

[4] DAVIS, B. C. Applicability of RELAP5/MOD3.2 to research reactors. Proceedings of the IAEA Regional Training Workshop on Safety Analysis Methodology and Computer Code Utilization, KINS, Daejeon, Republic of Korea, 2002.

[5] DIMARO, B.; PIERRO, F.; BOUSBIA SALAH, A.; D’AURIA, F. Analysis of a pump trip in a typical research reactor by RELAP5/MOD 3.3. Proceedings of the International Congress on Advances in Nuclear Power Plants (ICAPP-03), Cordoba, Spain, 2003.

[6] COSTA, A. L.; REIS, P. A. L.; PEREIRA, C.; VElOSO, M. A. F.; MESQUITA, A. Z.; SOARES, H. V.; Thermal-hydraulic analysis of the IPR-R1 TRIGA research reactor using a RELAP5 model. Nuclear Engineering and Design, v. 240, no. 6, p. 1487-1494, 2010.

[7] HAMIDOUCHE, T.; BOUSBIA-SALAH, A.; ADORNI, M.; D'AURIA, F. Dynamic calculations of the IAEA safety MTR research reactor Benchmark problem using RELAP5/3.2 code. Annals of Nuclear Energy, v. 31, no. 12, p. 1385-1402, 2004. 
[8] KHEDR, A.; ADORNI, M.; D'AURIA, F. The effect of code user and boundary conditions on RELAP calculations of MTR research reactor transient scenarios. Nuclear Technology and Radiation Protection, v. 1, p. 16-22, 2005.

[9] REIS, P. A. L.; COSTA, A. L.; PEREIRA, C.; et al. Assessment of a RELAP5 model for the IPR-R1 TRIGA research reactor. Annals of Nuclear Energy, v. 37, no. 10, p. 1341-1350, 2010.

[10]KONCAR, B.; MAVKO, B. Modeling of low-pressure sub cooled flow boiling using the RELAP5 code. Nuclear Engineering and Design, v. 220, no. 3, p. 255-273, 2003.

[11]HAMIDOUCHE, T.; BOUSBIA-SALAH A. RELAP5/3.2 assessment against low pressure onset of flow instability in parallel heated channels. Annals of Nuclear Energy, v. 33, no. 6, p. $510-520,2006$.

[12] HAMIDOUCHE, T., BOUSBIA-SALAH, A., SI-AHMED, E. K.; MOKEDDEM, M. Y.; D'AURIA, F. Application of coupled code technique to a safety analysis of a standard MTR research reactor. Nuclear Engineering and Design, v. 239, no. 10, p. 2104-2118, 2009.

[13] WOODRUFF, W. L.; HANAN, N. A.; SMITH, R. S.; MATOS, J. E. A comparison of the PARET/ANL and RELAP5/MOD3.3 codes for the analysis of IAEA benchmark transients. Proceedings of the International Meeting on Reduced Enrichment for Research and Test Reactors, Seoul, Republic of Korea, 1996.

[14]HEDAYAT, A.; DAVILU, H.; JAFARI, J. Loss of coolant accident analyses on Tehran research reactor by RELAP5/MOD3.2 code. Progress in Nuclear Energy, v. 49, no. 7, p. 511$528,2007$.

[15]ALLISON, C.; HOHORST, J. K.; ANTARIKSAWAN, A.; et al. Validation of RELAP/SCDAPSIM/MOD3.4 for research reactor applications. Proceeding of the 13th International Conference on Nuclear Engineering (ICONE 05), China, 2005.

[16]BELCHIOR JR., A.; SOARES, H. V.; FREITAS, R. L. Validation of the Relap5 Code for the Simulation of the Siphon Break Effect in Pool Type Research Reactors. 2019 International Nuclear Atlantic Conference - INAC 2019, Santos, SP, Brazil, 21-25 October 2019.

[17]SOARES, H. V. Avaliações de Segurança do Reator Multipropósito Brasileiro. Tese de Doutorado em Ciências e Técnicas Nucleares, Escola de Engenharia, Universidade Federal de Minas Gerais (UFMG), 2014. 